\title{
Impact of Communication in Organization to Readiness for Change: Caseof Research Organization $\mathrm{X}$
}

\author{
Mia Rahma Romadona ${ }^{1}$, Sigit Setiawan ${ }^{2}$ \\ Center for Science and Technology Development Studies, Indonesian Institute of Sciences (Pappiptek-LIPI), \\ Jakarta, Indonesia ${ }^{1,2}$ \\ 1'Romadona.mia@gmail.com,2²igitsetiawan@yahoo.com
}

\begin{abstract}
Changes in government research institutions are an interesting phenomenon and need to be studied. Like other government agencies, government research institutions have a bureaucratic and organizational culture and climate that is not easy to change. Organizational change cannot be accomplished if it is not supported by organizational readiness to change from individual level to organizational level. Organizational readiness as a medium and a tool for determining the success of change needs to be reviewed. The purpose of this research is how organizational communication conducted by research institute $X$ to impact on organizational readiness to change. The method used is mixed methods with survey about organizational readiness to change and depth interview and observation to see the phenomenon of change and organizational communication in research institute $\mathrm{X}$. The results obtained are communication within organizations that are not well managed and less effective have make readiness to organization change in research institution $\mathrm{X}$ becoming quite low. This indicate that organizational communication has an impact on organizational readiness to change in research institute $\mathrm{X}$.
\end{abstract}

Keyword: Organizational Change, Readyness to Change, Organizational Communication

\section{Introduction}

Since introduction of the Republic of Indonesia Presidential Regulation No. 81 of 2010 concerning Grand Design of Bureaucratic Reform in 2010-2025 has been passed, it applies to all government agencies, both ministries and non-ministries. Including also non-ministerial institutions engaged in research, one of them is the $\mathrm{X}$ research institution as the largest research institution in Indonesia. The $\mathrm{X}$ research institute has a business core that conducts research activities in basic up to applied research. The research institute $\mathrm{X}$ also carried out reforms in its organizational field in lieu of that regulation. This has an impact on the organizational order in the management of all organizational resources. 2018 is a very meaningful moment of change, namely the plan for reorganization in all aspects of the organization.

Organizational changes that are carried out as organizational reform activities are to be able to increase organizational productivity with the resources, they have to be able to perform optimally. The direction of change that refers to organizational effectiveness and efficiency is expected to increase scientific production and innovation technology for the development of science and 
technology in Indonesia by research institute $\mathrm{X}$. Organizational change that being done is including restructuring on organizational system changes, organizational policy changes, human resource management with redistribution plan in each work unit etc. The plan of change is a phenomenon that is important to be studied and understood as part of empirical studies of organizational development. The phenomenon of organizational change is linked to how organizational behaviour occurs with what factors have a positive and negative impact on the success of its implementation plan.

As an $\mathrm{X}$ research institute that has the largest research activity in Indonesia, conducting an activity plan for implementing organizational change is an interesting thing to review. This study examines in the form of organizational management studies to look at organizational communication factors that will impact the readiness of the organization to change.

\section{Methodology}

This study uses a mixed method approach used in social research with triangulation data analysis to express and interpret data from quantitative and qualitative. AlsoThis study uses case study approach to a phenomenon of organizational change in research institutions by in-depth interviews and observations. In addition, it also performs quantitative measurements with surveys regarding organizational readiness to change. This measurement involves the researcher as the population and on the other hand uses random sampling by involving researchers from all units of the research centre work unit in research institute $\mathrm{X}$.

Measurement of organizational readiness to change using adaptations from the Scale of Timmorand Zif [1] with a validity value of 0.75 and has been validated in several of their studies. The ORC scale with 6 item questions with a Likert scale, namely 6 levels of answer choices responded to by the subject of this study. The ORC scale measures three dimensions of formation, namely trigger identification, gearing up to take action, and action's degree of novelty. As for digging deeper into the ORC, in-depth interviews and observations were carried out as well as to explore organizational communication.

Data results from this research data are then processed and interpreted based on the forming dimensions with data triangulation method.

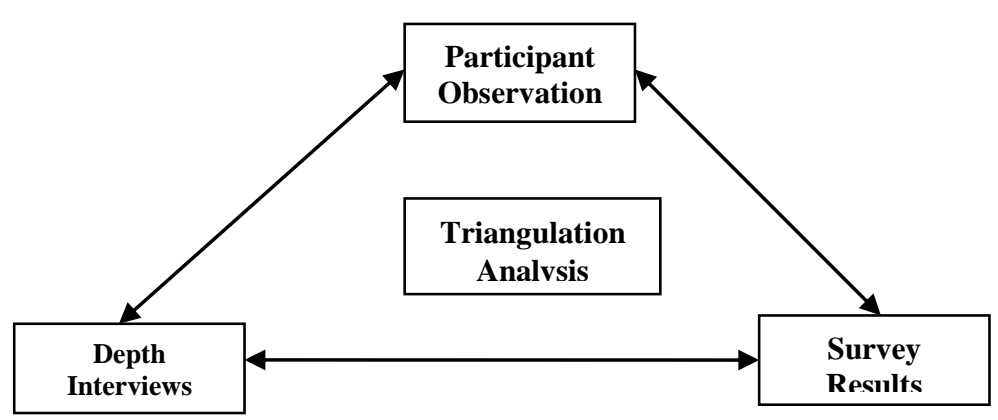

Fig. 1. Triangulation analysis

Triangulation analysis is a method used to analyse data from quantitative measurements from ORC and qualitative data from deepening ORC perceptions and organizational communication. From Creswell [2] and Neuman [3] the method of data triangulation analysis evolved into a new 
research method by leaving a parallel line that allows science to explain a significant percentage of existing phenomena and is still open to exploring critical issues that around the phenomena studied. So, this research uses the data triangulation analysis to help examine the phenomena of the collected data so that it can describe the critical issues in relation to the impact of organizational communication on the change readiness of research organizations $\mathrm{X}$.

The framework in this study is as follows.

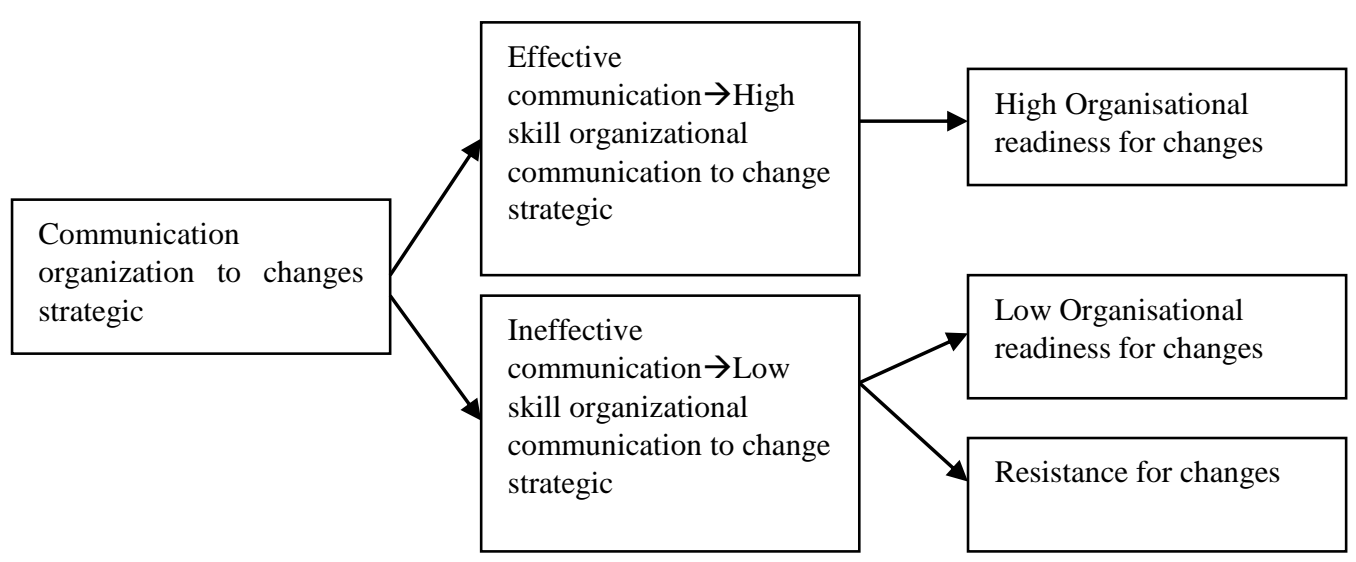

Fig. 2. Research Framework

Figure 2 explains the scope of the research conducted so that it can answer the questions in this study.

\section{Theoritical Discussion}

\section{a. Organizational Communication}

Organizational communication is the flow and process of communication in organizations related to the flow of communication based on organizational structure both from top to bottom or from the bottom up. Effective communication significantly helps managers in organizations to perform better in their basic functions as managers of organizations such as in planning, leadership, control, and organizational change activities. Effective communication skills can form managers to communicate future organizational plans so that all employees can perform to achieve a common goal in the organization. Effective organizational communication [4]; [5]; [6]; [7]can provide and increase the motivation of employees to finish their job well, be willing to perform optimally and perform well, besides providing information resources good, so that it can help employees in the decision making process in identifying and assessing alternative solutions or activities that will be carried out to solve the problem. In addition, it is also in helping employees in the socialization process with one employee with another or with the structural party, and can help control the process of organizational behaviour of employees to be able to be in accordance with the behavior expected by the organization. [8] argues that organizational communication skills are needed by change agents to communicate various information plans and implementation of organizational changes in internal or informal forums so as to minimize resistance and increase commitment to change in organizational members.

Orpen [8] argues in research that managers who have satisfaction and good work motivation will have a positive impact on organizational communication skills so that it will minimize 
information bias in the organization. Fahmi and Maroofi [9] argue that communication styles in organizations can influence the level of work involvement of managers. Clampitt [5] explains that organizational communication is important to do precisely to help organizations deliver various plans, strategies, and actions to members so that they are willing and willing to support and are committed to supporting organizational goals. Organizational communication strategies must pay attention to sensitive and psychological issues that cover issues of organizational change. Elving [7] argues that the function of communication is conveying messages and information to motivate people so that they are ready to change as expected by organizational change.

\section{b. Organizational Readiness}

The organizational readiness for change is one of the import variables that can give effect to organizational change success. Like the theory of changes from Lewins about the Process Organization changes model. Keidel [10]says changes have an organization changes construct to increase productivity and employee quality of life's. Porras and Robertson [11] explain that organizational change as a set of theories, values, strategies, and techniques to be able to change the work environment so as to encourage organizational development. Whereas Jones [6]argues that organizational change as an organizational process redesigns structure and culture to help and improve the effectiveness of achieving organizational goals.

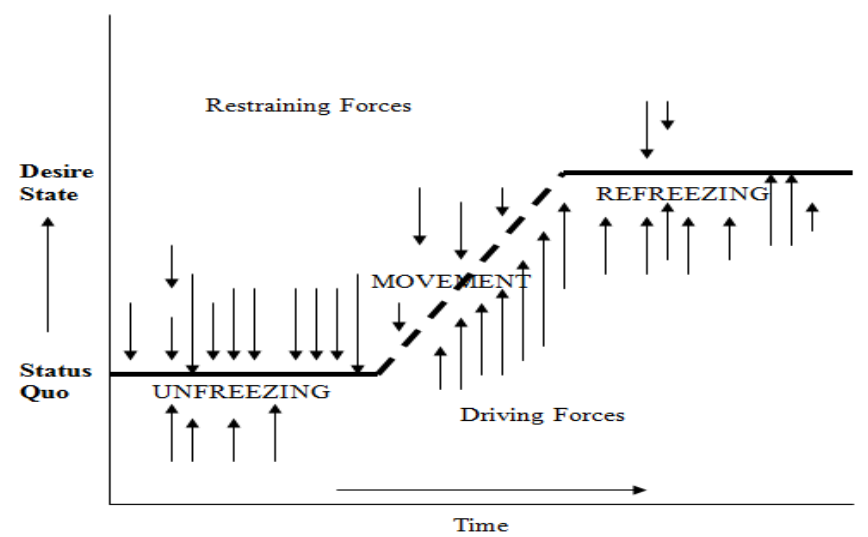

Fig. 3. Organizational Change Process from Lewin's Model 1951 (resourches: Jones, 2007)

Armenakins et. al. [12] and Lehman [1] develop and explore the readiness for organizational changes inspirations from Lewin's model [13] about the organization of change process models with three steps. The three steps of the Lewis model of organization changes are unfreezing, movement, and refreezing. Every step of the process of organization change can give us a description of how to plan and strategic change from an organization. The process of changes is like life cycles because of the dynamic and changes of environment form organization. This is reason why organizations should be aware of and be prepared to encounter change with flexibility to change too. 
Armenakis et al [12] and Chonko et al [8] explain that organizational readiness to change is as a cognitive concept that influences resistance behaviour or supports organizational change. So ORC is related to the collective belief of members of the organization to the organization's willingness to make changes [1]; Timmor [1] argue that ORC as a strategy orientation is used specifically to support organizational capacity effectively as an effort to support the achievement of organizational goals. Therefore, ORC as a concept of organizational behaviour that supports organizational change so that it is not just an attitude. Organizational readiness for changes is the initial process that must be carried out by the organization before implementing the change plan. Readiness to change organizationally is needed to prepare the initial stages for the success of the change process, although it does not guarantee success but can know the potential failure and reduce resistance to these changes.

Organizational readiness for changes are formed from three dimensions based on the theory of Armenakins et al. [12] and Chonko et al. [8] which are indicators of whether an organization is ready or not to make planned changes, namely : trigger identification, Gearing up to take action (preparing), and Action's degree of novelty. These three dimensions illustrate that in the process of preparing for organizational change, the internal organization, namely management, needs to identify the root causes of change, identify potential problems that will occur when changes are made, and identify problems that will arise after the changes are made. Then in trigger identification is related to how quickly the organization is able to identify things that can trigger change. While it is the stage of gearing to take action as a form of preparing for change, the organization needs to develop strategies to minimize possibilities that are not relevant or hinder organizational change. This is related to how much time is used to make the right call to start improving the implementation of change. In addition, the last stage of readiness is the action degree of novelty, namely the action of the organization to make changes as a form of novelty. So, this is related to the organization in making a change response by innovating.

Various previous studies explained that organizational communication is useful for communicating or providing information about strategies and plans for organizational change from managers to organizational members so that there is commitment and support from them [12]; [14]; [15]; [1]; [16]

The purpose of this study is to identify organizational communication carried out by research institute $\mathrm{X}$ to be able to support the readiness of organizations to change. From these objectives, the research question is how the role of organizational communication can support the readiness of research institutions $X$ to change? The benefit of this research is to be able to identify organizational communication factors that can hinder and support change readiness in research $\mathrm{X}$. Another benefit is to provide policy recommendations related to organizational communication strategies to be able to support research readiness $\mathrm{X}$ in making changes. In general, the benefits of this study are to be able to strengthen the theory and become an empirical basis for the role of organizational communication in the organization's readiness to change.

\section{Discussion}

Based on the measurement results regarding the readiness of the organization to change in research institute $\mathrm{X}$, it was discovered that 137 researchers from all levels of the first research position had responded, young researchers, middle researchers, and principal researchers. Based on the distribution of respondents' data in the survey are as follows: 


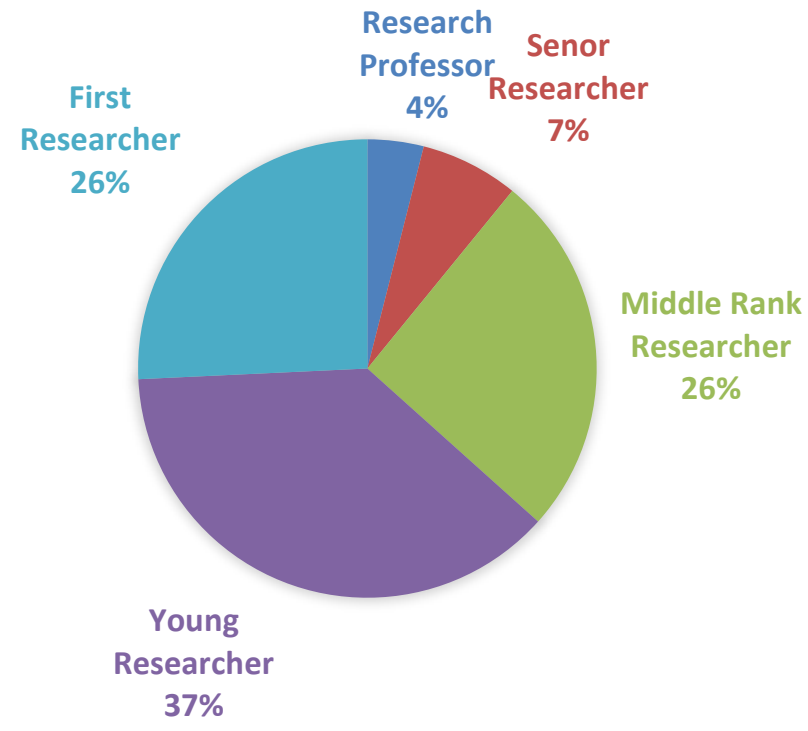

Fig. 4. Distribution of Researcher Based on Fungtional Level

The distribution of responses based on the functional positions of researchers seen from Figure 4 is that there are 137 researchers involved, namely the highest number of middle rank researchers as much as $38 \%$, then the first and young researchers the percentage of $26 \%$, the senior researchers there are $7 \%$ and research professors as much as $4 \%$. From the distribution of responses based on the level of functional positions of researchers, the most respondents were young researchers, while the least number of respondents were in the functional positions of researchers as research professors. 


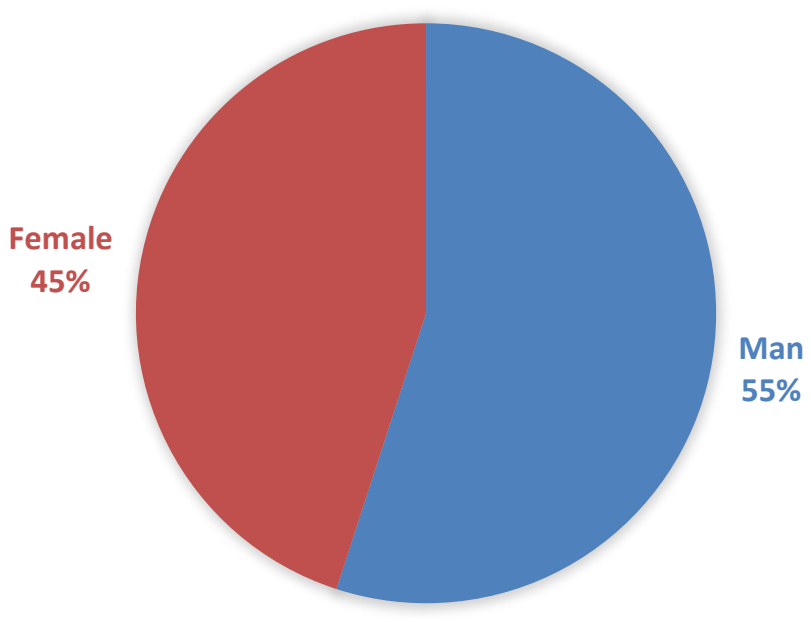

Fig. 5. Distribution of Researcher Based on Gender

Distribution of researcher respondents based on sex differences can be seen in Figure 5. The picture explains that female respondents were $45 \%$ and male respondents were $55 \%$ of the total respondents 137 researchers.

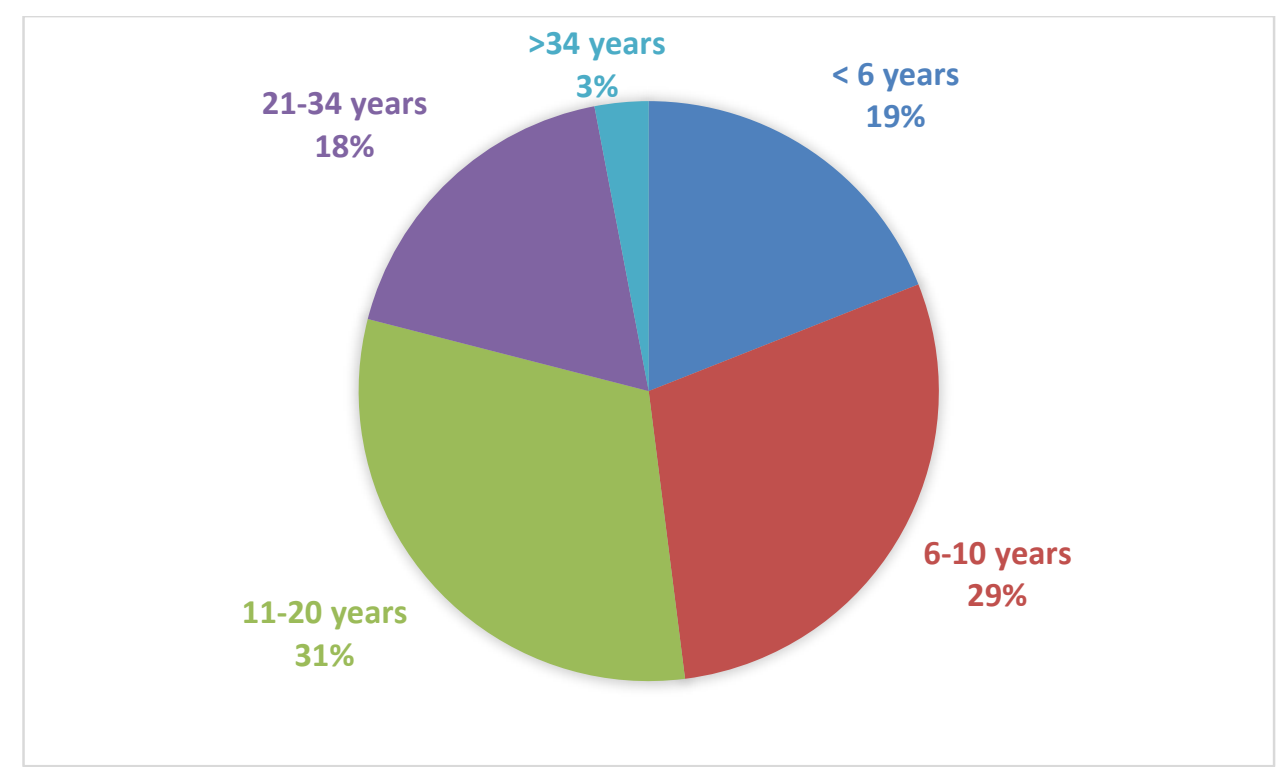

Fig. 6. Distribution of Researcher Based on Working Times

In addition, based on the distribution of researchers 'responses based on the duration of work, research institute X can be seen in Figure 6. Figure 6 explains the variations in the length of work 
of researchers working in research $\mathrm{X}$ glue, namely the highest number of researchers' responses in the range of 11-20 years of work 33\%, while the respondents who respond the least are those with more than 34 years of work, only 3\%. As for the duration of the researcher's work based on the other length of work is in the range of 6-10 years by $29 \%$, <6 years as much as 19\%, and 21-34 years by $18 \%$.

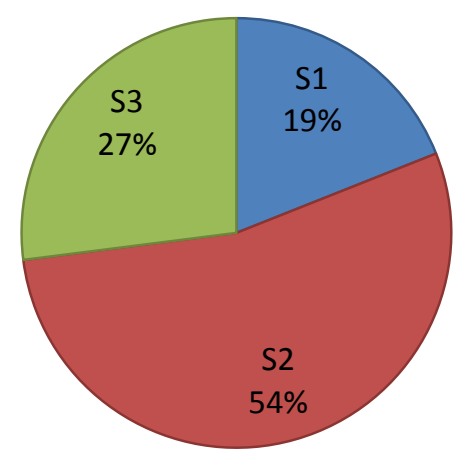

Fig. 7. Distribution of Researcher Based on Education Levels

The distribution of research respondents based on education level has variations, namely researchers with undergraduate education (S1) which is equal to $27 \%$, researchers with a graduate education level (S2) of 54\%, and researchers with a doctoral degree education (S3) of 19\%. The distribution can be concluded that the highest number of respondents is at the two-level education level.

Based on the distribution of responses seen from the functional levels, sex, length of work, and education level explained that respondents who assessed and perceived the readiness of the organization to change were represented. This can support the results of the assessment of the organization's readiness to change quite accurately because all elements of the researcher have been represented.

The results obtained explained that the organization's readiness to change in research institute $\mathrm{X}$ had a mean value of 3.79 so it was at the level of lacking and preparing for an organizational change plan. This explains that researchers' perceptions of research X's readiness to change are still low. This has implications for how the research institute management $\mathrm{X}$ will communicate about its organizational development strategies for all members of the organization. Data from the analysis can be seen in the following table:

Table 1: Results of organizational readiness to change based on its 3 dimensions

\begin{tabular}{|l|c|c|}
\hline \multicolumn{1}{|c|}{$\begin{array}{c}\text { Readyness to Change } \\
\text { Dimension }\end{array}$} & $\begin{array}{c}\text { The average value of the } \\
\text { organization's readiness to } \\
\text { change }\end{array}$ & Explanation \\
\hline Trigger Identification & 3.75 & Low \\
\hline $\begin{array}{l}\text { Gearing up to take action } \\
\text { preparing) }\end{array}$ & 3.85 & Low \\
\hline Action's degree of novelty & 3.77 & Low \\
\hline
\end{tabular}


Based on the results of the measurement of the organization's readiness to change in the $\mathrm{X}$ research institute, which is predicted by its researchers, it is illustrated that the organization has not been able to prepare a plan and strategy for change optimally. It was detailed with its three dimensions, namely research institute $X$ has not been able to identify the problems why institutional productivity, especially in the production of knowledge and utilization of research results is not optimal. researchers believe that research institute $X$ is still confused to be able to explore, map, and develop the potential of human resources, physical resources, and the resources of science and technology owned. In addition, the lack of ability of research institute $\mathrm{X}$ to appreciate the success of its researchers in developing science and technology. Besides being able to identify external problems, it has not been able to be accurately identified from the needs of its stakeholders, namely the government, academics, industry, and the community so that they have not been able to precisely determine the strategy in the future. The dimensions of gearing up to take action or process changes are perceived by researchers towards organizational readiness to change, namely organizations still cannot quickly correct errors in organizational management, so there are doubts among researchers about the ability of research institutions to be able to succeed in make organizational changes to be more effective and efficient. Some activities or programs have been carried out to improve and maximize productivity but have not been effective and tend to be considered not to have a significant impact on the organization. The final dimension is action degree of novelty perceived by researchers regarding their institutions, namely organizations are not optimally responsive to change both internally and externally so that existing innovations are still partial in that they are only in certain work units and have not been mutually integrated with each other. This has an impact on imbalance and the existence of disparities between work units in productivity and governance.

Based on the results of the interview regarding the readiness of research institute $\mathrm{X}$ to change in some researchers who were the subjects of the research, the results were obtained which explained several things as follows:

1. Research institute $X$ needs to pay attention to the three dimensions of the organization's willingness to change as a basis for developing organizational change strategies, namely identification of triggers (challenges), willingness to change, and actions to make changes.

2. The research institute $X$ still lacks the resources it has to support the organizational change plan

3. Research institute $X$ has not seriously mapped the potential and capacity of capabilities of the resources it has

4. Unidentified potential resources are developed, main resources, and potential resources

5. Research institute $X$ still uses the old pattern in managing the organization, so that the change plan is still considered to be less than optimal

6. There is an indication of high inertia to make changes from members of the organization, namely the majority of researchers

7. Desire changes only to the intrinsic motivation of individual researchers or members of organizations that are related to their needs

8. Age and duration of work affect perceptions about the readiness of research institutions $\mathrm{X}$ to change

9. There is a desire for researchers to change to a better direction in research institutions $\mathrm{X}$, so as to be able to increase productivity and have better competitive ability

10. The need for research institutions $X$ to make changes to be more adaptive to changes from internal and external sides 
Supporting the measurement results for ORC with a survey conducted on 137 researchers included in less categories, namely organizations perceived by organizations to be less prepared to plan and implement organizational changes. This is supported by extracting data in depth interviews which leads to the hope that researchers for organizations design changes that are more effective and communicate them openly and effectively. In addition, it was found that each individual researcher expects a better change in the organization but is still limited to the needs and perceptions of individual researchers so that it is not comprehensive. Then the need for change is done thoroughly from every aspect of the organization to be more productive and effective and efficient.

The phenomenon of organizational change is inseparable from how organizational communication activities are communication from management to all members and from organizational members to management to support success and minimize resistance. Organizational communication in institution $\mathrm{X}$ research was one of the factors that was explored to find out its impact on ORC research institute X. Interviews and observations were conducted on researchers who had responded to ORC measurements.

The results of the interview data and observations from a qualitative approach to organizational communication are as follows:

1. The pattern of weak interaction in each work unit and management affects organizational communication

2. Communication of organizations in research institutions $X$ is still weak and has not used communication skills optimally

3. There is a communication barrier between management and its members

4. Management is less able to use media that is effective in communicating information related to organizational change plans

5. Capacity of management capabilities in conducting organizational communication

6. Lack of smooth communication between work units makes obstacles in the delivery and response of the right information

7. Organizational communication is considered less open and only top-down

Based on the results of the interview above, it can be explained that organizational communication has an important role in the process of planning the implementation of organizational change in research institute $\mathrm{X}$. The results obtained regarding the description of organizational communication in research institutions $\mathrm{X}$ have not been effective and not optimal in the use of communication media. This has implications for the perception of researchers that communication in research institutions $\mathrm{X}$ is still less open, less effective, still lacking the ability of the management to inform organizational plans to members, so that it impacts on a lot of information that is responded to inappropriately. Then all of that will have an impact on the potential for resistance to change, so that the organization is considered to be not making optimal preparations in implementing the change plan.

The dynamics of organizational communication influence the readiness of the organization to change.

The policy change regarding the change in orientation of research results that are more tangible to be able to be diffused in the wider community is the basis for $\mathrm{X}$ research institutions to be able to increase the productivity of science and technology. The expected productivity of science and technology is not only on the production of knowledge, but also on the products of research that must be disseminated and commercialized to the wider community. That is why research institute $\mathrm{X}$ makes organizational changes to be more effective and efficient in achieving organizational 
goals, namely increasing the quantity and quality of research results that can be disseminated and commercialized.

Organizational change is the basis for the X-ray organization to conduct reengineering on the internal aspects of the organization. Researchers individually expect a more significant change in the management of research institutions $X$ in exploring the potential and utilizing the resources they have. Research institute X actually has a lot of resources that are unlimited and have advantages in the field of human resources, because it is a chosen human resource with a deep capacity of knowledge and skills in their fields, so that they have many achievements both inside and outside the country. However, the organization cannot yet see the potential and capital to develop the organization in the future. There are indications that the organization is still unable to map the capabilities and potential resources it has, so that it makes the organization experience difficulties and confusion in setting targets in the future.

The lack of optimal management of research institutions $\mathrm{X}$ in using the skills, abilities and use of organizational communication media makes information or messages about plans for implementing organizational change less properly conveyed. This was responded to by many members, namely researchers at research institute $\mathrm{X}$ became confused and doubted the direction of the change in the organization in the future. In addition, the existence of researchers perceives that organizational change needs to be done to improve the productivity of science and technology. But they also perceive that research institute $\mathrm{X}$ is less prepared for au primal organizational change. As in the ORC dimension, research institute $X$ is still not able to precisely identify organizational problems accurately and quickly, so that problem solving and decision-making plans are still considered inappropriate. The speed of research institute $\mathrm{X}$ to respond to changes and problems is still perceived to be slow, because many of the problems that have occurred so far have not been resolved thoroughly and there are protracted tendencies, because the strategy used is not appropriate. And the novelty activities of the organization have not been optimized, because organizational resources have not been properly explored. All of these have implications for the implementation of organizational change strategy strategies to be less than optimal in integrating organizational resources.

\section{Conclusions}

Organizational change is a common activity as a form that the organization is dynamic in responding to changes both from internal and external organizations. Organizational change cannot just happen to be able to successfully achieve the goals to be achieved from change. Organizational change needs careful planning and optimizing potential resources that can support the success of these changes. Organizational readiness to change needs to be in every organization to successfully implement changes. As research institute $\mathrm{X}$ is implementing the change plan. When viewed from the aspect of organizational communication, it is still not able to use optimal communication strategies, so that changes in the organization of the telephone become appropriate. But on the other hand, it becomes confusing in the direction of the goal that is considered unclear. This has implications for researchers' perceptions of ORC in research institutions $\mathrm{X}$ is still lacking, because organizations are considered not able to identify the root of the problem correctly, have not been able to map the potential resources of the organization, and have not been able to identify problems related to change. In addition, the organization is perceived as still not able to use and does not have the right strategy to achieve organizational goals. Therefore, $\mathrm{X}$ research institutions are perceived as having no change innovations that are in line with the needs of the organization in the future. That makes an obstacle in implementing the expected change plan. When organizational communication has not been able to be used optimally and effectively, the strategy for implementing organizational changes is hampered. So, it will bring 
up the lack of preparedness of the organization to make changes even if there is resistance from the members of the organization.

Based on the findings of this study explaining the important role of organizational communication skills from the management to be able to support the readiness of the organization to change. Therefore, the research team $\mathrm{X}$ needs to consider and use communication strategies as an important part of the change plan to be able to increase the readiness of the organization to change.

This research still needs to explore other aspects that explain organizational change. As for this study, it is only limited to exploring aspects of organizational communication and organizational readiness to change. The boundaries of the aspects studied in the study need to be studied in further research by exploring other aspects of organizational behaviour. So for further research there needs to be other aspects that need to be explored in order to explain the factors that support and weaken the organization's readiness to change.

\section{Acknowledgements}

This research is sourced from previous research conducted by the 2016 PAPPIPTEK-LIPI budget. The authors express many thanks to Pappiptek LIPI who have supported this research to be publicized. And acknowledgement to the research team who have supported and allowed to publish the results of the research.

\section{References}

[1] Y. Timmor And J. Zif, "Change Readiness: An Alternative Conceptualization And An Exploratory Investigation," Euromedjorunal Of Business, 5(2), 2010.

[2] J. W. Creswell, S. Trout, and J. E. Barbuti, A decade of mixed methods writings: A restrospective. Downloaded from Academy of Management Online. 2002.

[3] W. L. Neuman, Sosial research methods qualitative and quantitative approach, 6th ed. Boston: Allyn and Bacon, 2001.

[4] H. M. Z. Al-Bogami, "The relationship between transformational managemenet and communication skills among heads of departements of," KAU. Procedia Computer Science, vol. 65, pp. 1160-1164, 2015.

[5] P. G. Clampitt, Communication for Managerial Effectiveness: Challenges, Strategies, Solutions, Sixth Edition. SAGE: USA, 2017.

[6] J. D. Johnson, “Approaches to organizational communication structure," Journal of Business Research, vol. 25, pp. 99-113, 1992.

[7] W. J. L. Elving, "The role of communication in organizational change," Corporate Communicatioan An International Journal, vol. 10, no. 2, pp. 129-138, 2005.

[8] L. B. Chonko, E. Jones, J. A. Roberts, and A. J. Dubinsky, "The Role of Environmental Turbulence, Readiness for Change, and Salesperson Learning in the Success of Sales Force Change," Journal of Personal Selling \& Sales Management, vol. 22, no. 4, pp. 227-245, 2013.

[9] A. Fahmi and F. Maroofi, "Identity the relathionship between communication style of managers and job involvement," Journal of Novel Aoolied Sciences, vol. 3, no. 1, pp. 14801488, 2014.

[10] R. W. Keidel, "Theme appreciation as a construct for organizational change," Management Science, vol. 27, pp. 1261-1278, 1981. 
[11] J. I. Porras and P. J. Robertson, "Organizational development: theory, practice," in Handbook of industrial and organizational psychology, vol. 2, and research I. M. D. D. L. M. Hough, Ed. PaloAlto, CA: Consulting Psychologists Press, 1992, pp. 719-822.

[12] A. A. Armenakis, S. G. Harris, and MossholderKW, "Creating readiness for organizational change," Human Relation, vol. 46, no. 6, pp. 681-703, 1993.

[13] K. Lewin, Field Theory in Social Science: Selected Theoritical Papers, 1st ed. New York: Harper, 1951.

[14] B. Dym and H. Hutson, "Leveraging organizational readiness for change," System Thinkers, vol. 15, no. 9, pp. 2-6, 2004.

[15] S. Susansti, "Fakto-Faktor yang Berhubungan dengan Pemanfaatan Pelayanan Posyandu Lansia," in Posyandu Lansia, 2011.

[16] P. M. Swiercz, "Research Update: Strategic HRM.Human Resource," Planning, vol. 18, no. 3, pp. 53-59, 1995. 